REVIEW ARTICLE

\title{
Tuberculosis: Development of New Drugs and Treatment Regimens
}

\author{
Soedarsono \\ Department of Pulmonology and Respiratory Medicine, Faculty of Medicine, Universitas Airlangga/Dr. Soetomo \\ General Hospital, Surabaya, Indonesia.
}

\section{ARTICLE INFO}

Article history:

Received 06 January 2021

Received in revised form 22 January

2021

Accepted 27 January 2021

Available online 30 January 2021

Keywords:

TB and DR-TB regimen,

New drugs and treatment regimens, Repurposed drugs.

\begin{abstract}
Tuberculosis (TB) still becomes a public health crisis. Drug-resistant TB (DR-TB) becomes a concern as the increasing DR-TB cases in countries with high TB burden. The 2017 World Health Organization (WHO) guideline recommended a combination of TB treatment consisting of 2 months of intensive phase with isoniazid $(\mathrm{H})$, rifampisin $(\mathrm{R})$, pyrazinamid (Z), and ethambutol (E), followed by 4 months of continuation phase

with HR daily. WHO has updated DR-TB treatment guidelines several times. In 2016, WHO recommended shorter regimen and individual regimen based on certain conditions. The most updated $2020 \mathrm{WHO}$ guideline recommended the short regimen consisting of all oral drugs as well as changes in the grouping of medicines used in DR-

TB regimens in longer/individual regimens. Bedaquiline, delamanid, pretomanid, and sutezolid are new drugs which have been studied for their uses as anti-TB drugs (ATD). Bedaquilin and delamanid, which have passed phase 3 trials, have been approved and recommended by WHO for DR-TB treatment. Repurposed drugs have been used for DR-TB treatment during the time of evaluation of drugs list and regimens for DR-TB treatment. Fluoroquinolones, clofazimine, linezolid, carbapenem, amoxicillin/clavulanic acid are repurposed drugs. TB and DR-TB management will be updated at any time, based on the latest findings in studies, to evaluate and improve the effectiveness of current treatments. Prevention of active TB disease by the treatment of latent TB infection (LTBI) is also a critical component of the end TB strategy by WHO. Therefore, the development of new drugs for the LTBI treatment is also needed
\end{abstract}

\section{INTRODUCTION}

Tuberculosis (TB) continues to be a public health crisis worldwide. Globally, an estimated of 10 million TB cases is reported with 1.2 million mortality cases in $2019 .{ }^{1}$ The number of drug-resistant TB (DR-TB) cases increase every year. Combination of rifampisin $(\mathrm{R})$, isoniazid $(\mathrm{H})$, pirazynamide (Z), ethambutol (E) with or without streptomycin (S) is a standardized first line regimen in drug-sensitive TB (DS-TB). Multi-Drug Resistant TB (MDR-TB) is defined as TB caused by strains of Mycobacterium tuberculosis which are resistant to at least $\mathrm{R}$ and $\mathrm{H}$, two of the most potent first line anti-TB drugs. ${ }^{2}$ Indonesia is one of 30 countrieswith high TB burden in the world and is in the $2^{\text {nd }}$ rank in the world with 845,000 TB cases, while DR-TB cases is in the $5^{\text {th }}$ rank with 24,000 cases in $2019 .{ }^{1}$ TB treatments aim to cure patients, prevent complications and death, avoid recurrence, reduce the potential for transmission to susceptible people, and limit the emergence and spread of drug-resistant strains.

Current treatment for DS-TB, which consists of isoniazid $(\mathrm{H})$, rifampicin $(\mathrm{R})$, ethambutol $(\mathrm{E})$ and pyrazinamide (Z) for 6 months (2HREZ/4HR), shows high cure rates at around $90-95 \% .^{3}$ Anti-TB drugs also cause side effects from mild to severe. Problems with compliance, sub-optimal drug levels, and tolerability can lead to resistance. Shorter and more tolerated regimens are desperately needed to increase adherence and reduce loss to follow-up both DS-TB and DR-TB cases. ${ }^{4}$ Effectiveness of TB treatment depends on combinations of several bactericidal drugs and sterilizing activity in an adequate duration, to keep antimicrobial efficacy while preventing drug-resistant mutants and achieve permanent cure. $^{5}$ 
New TB drugs and regimens are urgently needed to improve cure rates and shorten the treatment of both drug-susceptible (DS) and drug-resistant (DR) TB (currently at least 6 to 9 months respectively). Regimens that consist of entirely new drugs will be an important therapeutic advance, because they will reduce the need of drug-susceptibility testing (DST). ${ }^{6}$ The current development of shorter and simpler treatments with a combination of new drugs and existing drugs requires detailed information about the safety and toxicity of each drugs; potential drug interactions; potential drug resistance when used for treatment; and its use in certain patients such as HIV, pregnant women, and children. ${ }^{7}$

The current research is underway to develop a shorter, more effective, safer, and more tolerated combination of treatments. ${ }^{3}$ Treatment of DR-TB is challenging as it needs combinations of several second line anti-TB drugs with a longer duration, high cost, and more adverse effects, and high rate of loss to follow-up cases. WHO has updated the guideline of DR-TB several times in 2006, 2011, 2016, and currently in 2020. The 2016 guideline of DR-TB recommended shorter regimen and individual regimen under specific conditions. ${ }^{8}$ In 2020, WHO recommended shorter regimen consisted of fully oral regimens and changes in grouping DR-TB drugs in making longer/individual DR-TB regimens. Fully oral regimens become the preferred option for most patients. Three medicines - fluoroquinolones (levofloxacin or moxifloxacin), bedaquiline, and linezolid - are strongly recommended in a longer regimen, completed by other medicines which are relatively safe. ${ }^{9}$ The success of the treatmentis positively associated with the use of linezolid(adjusted risk difference 0.15 , 95\% CI 0.11-0.18),

levofloxacin $(0.15,0.13-0.18)$, carbapenems $(0.14,0.06$ $0.21)$, moxifloxacin $(0.11,0.08-0.14)$, bedaquiline $(0.10$, $0.05-0.14)$, and clofazimine $(0.06,0.01-0.10)$. There is a significant association between reduced mortality andthe use of linezolid $(-0.20,-0.23$ to -0.16$)$, levofloxacin $(-0.06,-0.09$ to -0.04$)$, moxifloxacin $(-0.07,-0.10$ to $0.04)$, or bedaquiline $(-0.14,-0.19$ to -0.10$){ }^{10}$

\section{Treatment of Drug Sensitive Tuberculosis}

Treatment regimen for DS-TB consists of a 2month intensive phase with daily HRZE, followed by a 4month continuation phase with HR. ${ }^{3,11}$ WHO updated the DS-TB guideline in 2017 as follows:
- In DS pulmonary TB patients, regimens containing fluoroquinolone as performed in four studies; 4MfxHRZ, 4MfxRZE, 2MfxRZE / 2 (Mfx + RFP), 2MfxRZE / 4 (Mfx + RFP), 2GfxHRZ / 2GfxHR, 2 (GfxHRZ) / 2 (GfxHR), 2 (MfxHRZ) / 2 (MfxHR) are not recommended. (E: ethambutol, Gfx: Gatifloxacin, H: isoniazid, Mfx: moxifloxacin, R: rifampicin, RFP: rifapentine, $\mathrm{Z}$ : pyrazinamide). The regimen contains rifampicin (2HRZE / 4HR) remains the recommended regimen.

- The use of FDC is recommended to be administered for DS-TB treatment.

- In all DS pulmonary TB patients, the use of threetime weekly dosage is not recommended in both the intensive and continuation phases.

- In DS pulmonary TB patients with HIV infection and receiving ARV (antiretroviral) therapy during TB treatment, a standard 6-month treatment is recommended, compared with an extension of the duration of treatment 8 months or more.

In patients who need re-treatment, category 2 WHO regimens should no longer be given, the choice of regimen is considered based on DST.

The 2016 ATS/IDSA guidelines stated differently than the 2017 WHO guidelines in terms of duration of treatment in the continuation phase. Sputum culture examination results at the end of intensive phase (2 months) are related to the possibility of recurrence after the completion of TB treatment. Patients with cavity on chest X-ray at the initial treatment and positive cultures after 2 months of treatment are risk factors of relapse by $20 \%$, compared with pulmonary TB patients without these risk factors by $2 \%$. Based on this consideration, the expert team's opinion was to extend the continuation phase with $\mathrm{H}$ and $\mathrm{R}$ for 3 months to reduce the possibility of relapse. ${ }^{12}$ High doses of rifampicin andrifapentine have been studied to shorten TB treatment. In the PanACEA MAMS-TB-01 trial, rifampicin $35 \mathrm{mg} / \mathrm{kg}$ per day which added to standard doses of isoniazid, pyrazinamide, and ethambutol yielded an improved hazard ratio for stable culture conversion in liquid medium over 12 weeks (hazard ratio 1.75 , 95\% CI 1.21-2.55). However, the effect on culture status at 8 weeks using solid medium ( $10 \%$ positive $v s 15 \%$ incontrols) was predicted to cause a relapse rate of $13 \%$ ifonly administered for 4 months. In studies of rifapentine

$1.200 \mathrm{mg}$ once a day proposed for a phase 3 trial 
(NCT02410772) also resulted in $10 \%$ of patients with positive cultures using solid medium at 8 weeks in a phase 2 trial. Regimens resulting in 13\% relapse cases are not likely to be accepted by TB control programmes. ${ }^{6}$

\section{Treatment of Drug Resistant Tuberculosis}

WHO has updated classification of anti-DR TB drugs several times. The previous WHO guideline classified anti DR-TB drugs into 5 main groups based on its effectiveness and safety. This classification was recommended in 2006 and was updated in 2008, 2011, 2016, 2018, and 2020.

The current WHO guideline recommended 2 options of DR-TB treatment which are shorter and longer/individual regimen. Based on the available evidence, the shorter regimen can be a preferred option for patients with confirmed MDR/RR-TB (with at least confirmed resistance to rifampicin), for whom resistance to fluoroquinolones has been ruled out, in the following situations; without resistance or suspectedineffectiveness of a medicine in the shorter regimen (except isoniazid resistance); without exposure to previous treatment with second-line medicines in the regimen for more than 1 month (unless susceptibility to these medicines is confirmed); with no extensive TBdisease and with no severe extrapulmonary TB; not pregnant; and if a child, aged 6 years or more. ${ }^{9,13}$ Shorter regimens consist of: ${ }^{9}$

\section{Bdq with 4-6 Lfx/Mfx-Cfz-Z-E-H high dose-Eto/ 5 Lfx/Mfx-Cfz-Z-E}

(Bdq = Bedaquilline; Lfx = Levofloxacin; $\mathrm{Mfx}=$ Moxifloxacin; $\mathrm{Cfz}=$ Clofazimin; $\mathrm{Z}=$ Pirazinamid; $\mathrm{H}=$ Isoniasid; $\mathrm{E}=$ Etambutol; $\mathrm{H}=$ Isoniazid; Eto = Etionamid)

A study in Cameroon showed high effectiveness of the shorter regimen, among 150/236 treated patients with eligible STR, 134 (89\%) successfully completed the treatment, 10 patients died, 5 patients were loss to followup, 1 patient failed the treatment, and no relapse cases. The main adverse effect was hearing impairment on 46/106 (43\%) patients. $^{14}$ Standardized 12-month treatment for MDR-TB was highly effective and well tolerated in patients not previously exposed to secondline drugs in Nigeria, and the main adverse effects were vomiting (26.2\%) and hearing impairment (20\%) but no treatment had to be stopped and no relapse cases. ${ }^{15}$

Currently, the used of Mfx in STR are still debatable due to the presence of prolonged QT as an adverse effect. A study shows that Mfx is more likely to cause QTc prolongation than the other fluoroquinolones (FQs), although FQ is likely to be the most effectivedrug against MDR-TB. The risk of QTc prolongation with the FQs is higher when there are electrolyte imbalances and when other QTc prolonging medicationsare used. ${ }^{16}$

\section{Grouping Anti-Tuberculosis Drugs and Composing Individual Regimen}

WHO has changed the grouping of drugs to make an individualized regimen based on the efficacy hierarchy of each drug. This change was made based on scientific evidence obtained from quality research results. Bedaquiline did not appear to be one of the maindrugs of choice in making a combination of DR-TBtreatment at the beginning of the 2008 DR-TB guidelines, but was changed in the 2020 guidelines as bedaquiline becomes the main drug of choice. Kanamycin and capreomycin, which were originally used as the main drugs in making DR-TB treatmentregimens, are no longer recommended as one of the DR-TB drugs in DR-TB regimens. Table 1 below is a grouping of TB drugs according to their hierarchy and the steps to make regimens.

Injection drugs are no longer a priority in making individualized MDR-TB regimens. Kanamycin and capreomycin are no longer recommended, thus an entirely oral regimen is the preferred choice by patients. Three drugs such as fluoroquinolone (levofloxacin or moxifloxacin), bedaquilin, and linezolid are strongly recommended for use in individualized regimens. In MDR/RR-TB patients on longer regimens, a total treatment duration of $18-20$ months is suggested formost patients; the duration may be modified according to the patient's response to therapy. In multidrug- or rifampicinresistant tuberculosis (MDR/RR-TB) patientson longer regimens, the performance of sputum culturein addition to sputum smear microscopy is recommended to monitor treatment response. It is desirable for sputum culture to be repeated at monthly intervals. ${ }^{9}$ The guideline in Indonesia recommended 5 drugs in the intensive phase and 4 drugs in the continuation phase. 
Table 1. Grouping of medicines recommended for use in longer MDR-TB regimens ${ }^{9}$

\begin{tabular}{|c|c|c|}
\hline Groups & Medicine & Steps \\
\hline A & $\begin{array}{l}\text { Levofloxacin (Lfx) OR } \\
\text { Moxifloxacin (Mfx) } \\
\text { Bedaquiline (Bdq) } \\
\text { Linezolid (Lzd) }\end{array}$ & Include all three medicines \\
\hline B & $\begin{array}{l}\text { Clofazimine }(\mathrm{Cfz}) \\
\text { Cycloserine }(\mathrm{Cs}) \text { OR } \\
\text { Terizidone (Trd) }\end{array}$ & Add one or both medicines \\
\hline $\mathrm{C}$ & $\begin{array}{l}\text { Ethambutol (E) } \\
\text { Delamanid (Dlm) } \\
\text { Pyrazinamide (Z) } \\
\text { Imipenem-Cilastatin (Ipm-Cln) OR Meropenem (Mpm) } \\
\text { Amikacin (Am) OR Streptomycin (S) } \\
\text { Ethionamide (Eto) OR } \\
\text { Prothionamide (Pto) } \\
\text { p-aminosalicylic acid (PAS) }\end{array}$ & $\begin{array}{l}\text { Add to complete the regimen and } \\
\text { when } \\
\text { medicines from Groups A and B } \\
\text { can not be used }\end{array}$ \\
\hline
\end{tabular}

Table 2. Clinical strategy to build an individualized treatment regimen for MDR TB ${ }^{17}$

- Build a regimen using 5 or more drugs

- Choice of drugs is contingent on capacity to appropriately monitor for significant adverse effects, patient comorbidities, and preference/values (choices therefore subject to program and patient safety limitations)

- In children with TB disease who are contacts of infectious MDR-TB source cases, the source case's isolate DST result should be used if an isolate is not obtained from the child.

- TB expert medical consultation is recommended (ungraded good practice statement)

\begin{tabular}{|c|c|}
\hline Step 1: Choose 1 fluoroquinolone & $\begin{array}{l}\text { Levofloxacin } \\
\text { Moxifloxacin }\end{array}$ \\
\hline Step 2: Choose both of these prioritized drugs & $\begin{array}{l}\text { Bedaquiline } \\
\text { Linezolid }\end{array}$ \\
\hline Step 3: Choose both of these prioritized drugs & $\begin{array}{l}\text { Clofazimine } \\
\text { Cycloserine/ terizidone }\end{array}$ \\
\hline $\begin{array}{l}\text { Step 4: If a regimen cannot be assembled with five } \\
\text { effective oral drugs, and the isolate is susceptible, use one } \\
\text { of these injectable agents }\end{array}$ & $\begin{array}{l}\text { Amikasin } \\
\text { Streptomycin }\end{array}$ \\
\hline $\begin{array}{l}\text { Step 5: If needed or if oral agents preferred over } \\
\text { injectable agents in Step 4, use the following drugs }\end{array}$ & $\begin{array}{l}\text { Delamanid } \\
\text { Pyrazinamide } \\
\text { Ethambutol }\end{array}$ \\
\hline $\begin{array}{l}\text { Step 6: If limited options and cannot assemble a regimen } \\
\text { of five effective drugs, consider use of the following } \\
\text { drugs }\end{array}$ & $\begin{array}{l}\text { Ethionamide atau prothionamide } \\
\text { Imipenem-cilastatin/ clavulanate or meropenem/ } \\
\text { clavulanate } \\
\text { p-Aminosalicylic acid } \\
\text { High-dose isoniazid }\end{array}$ \\
\hline $\begin{array}{l}\text { The following drugs are no longer recommended for } \\
\text { inclusion in MDR-TB regimens }\end{array}$ & $\begin{array}{l}\text { Capreomycin dan kanamycin } \\
\text { Amoxicillin/clavulanate (when used without a } \\
\text { carbapenem) } \\
\text { Azithromycin and clarithromycin }\end{array}$ \\
\hline
\end{tabular}

Both ATS (2019) and WHO (2020) guidelines recommended new drugs or repurposed oral agents with greater efficacy and do not recommend the use of injection drugs. ${ }^{9,17}$ Clinical step to make an individualized regimen recommended by ATS in determining certain drugs is presented in Table 2 below.

Fluoroquinolones (levofloxacin or moxifloxacin), bedaquilin, and linezolid are recommended as the main drugs in individualized regimens. Delamanid is a drug currently used to complete treatment regimens and when drugs in groups A and B can not be used (Table 1). The use of bedaquiline is acceptable for children aged atleast 6 years old and delamanid is for 3 years old children. Further study for bedaquiline is needed to determine optimal pharmacokinetic in children, cost effectiveness, and optimization of the duration in both adults and children, while delamanid is needed to be studied for its role in MDR TB regimens in children (pharmacokinetics/pharmacodynamics), patients with HIV, pregnant women, drug resistance mechanisms, and the optimization of the duration both in adults and children. Knowledge about the safety of bedaquiline and 
Table 3. Summary of recommendations on drugs for use in a treatment regimen for patients with multidrug-resistant tuberculosis, including strength of recommendation, certainty in the evidence, and relative effects on death and treatment success. $\mathrm{OR}=$ Adjusted Odds Ratio; $\mathrm{CI}=$ Confidence Interval $^{17}$

\begin{tabular}{|c|c|c|c|c|c|}
\hline \multirow[b]{2}{*}{ Drug/Drug Class } & \multicolumn{2}{|c|}{ Recommendation } & \multirow[b]{2}{*}{$\begin{array}{l}\text { Certainty in the } \\
\text { evidence }\end{array}$} & \multirow{2}{*}{$\begin{array}{c}\text { Relative } \\
\text { (95\% CI) } \\
\text { Death } \\
\end{array}$} & \multirow{2}{*}{$\begin{array}{c}\text { Relative }(95 \% \\
\text { CI) Success }\end{array}$} \\
\hline & FOR & AGAINST & & & \\
\hline Bedaquiline & Strong & & Very Low & $0.4(0.3-0.5)$ & $2.0(1.4-2.9)$ \\
\hline $\begin{array}{l}\text { Fluoroquionone: } \\
\text { Moxifloxacin }\end{array}$ & Strong & & Very Low & $\mathbf{0 . 5}(0.4-0.6)$ & $3.8(2.8-5.2)$ \\
\hline $\begin{array}{l}\text { Fluoroquionone: } \\
\text { Levofloxacin }\end{array}$ & Strong & & Very Low & $\mathbf{0 . 6}(0.5-0.7)$ & $4.2(3.3-5.4)$ \\
\hline Linezolid & Conditional & & Very Low & $\mathbf{0 . 3}(0.2-0.3)$ & $3.4(2.6-4.5)$ \\
\hline Clofazimine & Conditional & & Very Low & $\mathbf{0 . 8}(0.6-1.0)$ & $1.5(1.1-2.1)$ \\
\hline Cycloserine & Conditional & & Very Low & $\mathbf{0 . 6}(0.5-0.6)$ & $\mathbf{1 . 5}(1.4-1.7)$ \\
\hline $\begin{array}{l}\text { Injection: } \\
\text { Amikacin }\end{array}$ & Conditional & & Very Low & $\mathbf{1 . 0}(0.8-1.2)$ & $2.0(1.5-2.6)$ \\
\hline $\begin{array}{l}\text { Injection: } \\
\text { Streptomycin }\end{array}$ & Conditional & & Very Low & $0.8(0.6-1.1)$ & $1.5(1.1-2.1)$ \\
\hline Ethambutol & Conditional & & Very Low & $\mathbf{1 . 0}(0.9-1.2)$ & $\mathbf{0 . 9}(0.7-1.1)$ \\
\hline Pyrazinamide & Conditional & & Very Low & $0.7(0.6-0.8)$ & $\mathbf{0 . 7}(0.5-0.9)$ \\
\hline $\begin{array}{l}\text { Injection: } \\
\text { Carbapenem with } \\
\text { clavulanic acid }\end{array}$ & Conditional & & Very Low & $\mathbf{1 . 0}(0.5-1.7)$ & $4.0(1.7-9.1)$ \\
\hline Delamanid & $\begin{array}{l}\text { Concur with WHO } \\
\text { conditional } \\
\text { recommendation }\end{array}$ & & & & \\
\hline $\begin{array}{l}\text { Ethionamid } \\
\text { Prothionamide }\end{array}$ & & Conditional & Very Low & $\mathbf{0 . 9}(0.8-1.0)$ & $\mathbf{0 . 8}(0.7-0.9)$ \\
\hline $\begin{array}{l}\text { Injection: } \\
\text { Kanamycin }\end{array}$ & & Conditional & Very Low & $1.1(0.9-1.2)$ & $0.5(0.4-0.6)$ \\
\hline $\begin{array}{l}p \text {-Aminosalicylic } \\
\text { Acid }\end{array}$ & & Conditional & Very Low & $1.2(1.1-1.4)$ & $\mathbf{0 . 8}(0.7-1.0)$ \\
\hline $\begin{array}{l}\text { Injection: } \\
\text { Capreomycin }\end{array}$ & & Conditional & Very Low & $1.4(1.1-1.7)$ & $\mathbf{0 . 8}(0.6-1.1)$ \\
\hline $\begin{array}{l}\text { Macrolide: } \\
\text { Azithromycin } \\
\text { Clarithromycin }\end{array}$ & & Strong & Very Low & $1.6(1.2-2.0)$ & $\mathbf{0 . 6}(0.5-0.8)$ \\
\hline $\begin{array}{l}\text { Amoxicillin- } \\
\text { clavulanat }\end{array}$ & & Stong & Very Low & $1.7(1.3-2.1)$ & $\mathbf{0 . 6}(0.5-0.8)$ \\
\hline
\end{tabular}

delamanid in pregnant and nursing women is very rare, thus it is recommended to use individualized regimens by using drugs with a guaranteed safety profile. The results of treatment during pregnancy and supervision after childbirth are also needed to be documented to provide information on MDR-TB treatment recommendations in future pregnancy. ${ }^{9}$

American Thoracic Society (ATS) have grouped the drugs list used for DR-TB, including a list of not recommended drugs. Table 3 below is a recommendation of MDR TB drugs. ${ }^{17}$

The guideline of DR-TB recommended by ATS (2019) and WHO (2020) have some differences as follows: ${ }^{9,17}$
- WHO recommendations are applied for MDR and RR-TB. Guideline of ATS/CDC/ERS/IDSA does not recommend DR-TB treatment guideline for rifampinresistant patients, thus it needs to be proved with the presence of isoniazid resistance.

- The minimum numbers of drugs likely to beeffective at the start of treatment are 5 in the ATS/CDC/ERS/IDSA guidelines and 4 in the WHO guidelines.

- Linezolid and bedaquiline are strongly recommended by WHO. ATS/CDC/ERS/IDSA agrees with the WHO recommendation that delamanid can be used for MDR-TB treatment. 
- Composing a standardized individual regimens between WHO and ATS/CDC/ERS/IDSA is different.

- WHO maintains the recommendation on the standardized 9-11 month shorter regimen under specific conditions, whereas ATS/CDC/ERS/IDSA cannot make a recommendation for or against the shorter regimen compared with individualized regimens.

- For patients with isoniazid-resistant TB, WHO does not recommend providing a shorter duration of pyrazinamide use under situations as recommended by ATS/CDC/ERS/IDSA guideline.

Although WHO recommends evaluation of drug resistance, their guideline accepts that globally empirical regimens will continue to be used. ATS/CDC/ERS/IDSA guideline requires microbiological data to create a regimen suitable for the individual patient's strain of tuberculosis. ${ }^{17}$

Recommendations regarding the composition, duration, and monitoring of individualized regimens of MDR-TB are applicable generally for children, adults, people with HIV-AIDS, and for patients with RR/MDRTB who are resistant to fluoroquinolones or other drugs, and people under specific conditions. Currently, bedaquilin can be given to children aged $\geq 6$ years old and delamanid can be given starting from the age of 3 years old children. The regimen is substantially different in terms of composition and recommended duration, which can be investigated further in an operational research.

\section{The New Compounds, Bedaquiline, Delamanid, Pretomanid, and Related Pipeline}

Regimens which consist of entirely new drugswill be an important therapeutic advance because they will reduce the needs for DST. Two new drugs (bedaquilineand and delamanid) have passed phase 3 trials and have been approved for MDR-TB treatment by WHO.

Two new compounds have entered phase 1 trials: Q203, a novel ATP synthetase inhibitor (ClinicalTrials.gov NCT02530710), and TBA-354, a nitroimidazole (NCT02606214). However, as of January 2016, the only study of TBA-354 had been suspended. So far, studies of SQ109 — an asymmetrical diamine- have not shown antituberculosis activity in sputum, alone or in combination with rifampicin over 14 days, either in rifampicin-containing regimens over 3 months. ${ }^{6}$

Bedaquiline is the first novel drug that has been

conditionally approved for treating adult pulmonary MDR-TB by US Food and Drug Administration (FDA) in December 2012 and by European Medicines Agency (EMA) in March 2014. The clinical evidence for using bedaquiline mainly came from one phase II clinical trial

performed in two stages, which showed that adding bedaquiline to a standard MDR-TB treatment regimen

significantly decreased the time to sputum culture conversion and significantly increased the proportion of patients with culture conversion from $9 \%$ to $48 \%$ at 8 weeks. $^{18}$

Delamanid is a derivative of metronidazole and a nitroimidazopyran and was approved by EMA in November 2013 for conditional use in the treatment of MDR-TB. The clinical evidence for delamanid use is based on short-term phase II clinical trial data, involving 481 MDR-TB patients, which showed a higher proportion of sputum culture conversion. An open-label extension of this phase II trial showed that delamaniduse for more than 6 months, in comparison with use for less than 2 months, significantly increased the proportion with favourable outcomes (cure or treatment completion) from $55 \%$ to $74.5 \%$ and significantly reduced mortality from $8.3 \%$ to $1.0 \%$. Delamanid significantly prolongs QT interval, thus it is important toincrease vigilance when combining delamanid with bedaquiline, clofazimine, and fluoroquinolones(especially moxifloxacin). ${ }^{18}$

Pretomanid is a nitroimidazole developed by TB Alliance and is being considered as a component in TB and MDR-TB regimens. This agent is being studied for clinical trials on TB and DR-TB. ${ }^{3}$ A phase II randomized controlled trial of Early Bactericidal Activity (EBA) (NC003) involving patients with smear-positive pulmonary TB suggested that EBA of pretomanid was highly dependent on its synergy with pyrazinamide, and a triad of pretomanid, moxifloxacin, and pyrazinamide gave the highest EBA, thereby suggesting its potential for further clinical trials. ${ }^{18}$

Sutezolid is a linezolid analogue initially developed for evaluation of better potential in vivo activity and less toxicity in comparison with linezolid. With a substantially lower Minimum Inhibitory 
Concentration (MIC) against Mycobacterium tuberculosis and reduction of MIC in acidic $\mathrm{pH}$,sutezolid has demonstrated a higher bactericidal activity than linezolid, as well as perhaps a potential sterilising activity. The whole blood bactericidal activity of sutezolid $600 \mathrm{mg}$ twice daily is higher than linezolid 300 $\mathrm{mg}$ once daily. Although EBA of sutezolid is significantly lower than that of the standard regimen, a whole blood bactericidal activity assay has demonstratedits synergistic activity with pyrazinamide. Sutezolid does not appear to cause QT interval prolongation or bone marrow suppression, although there are stillconcerns regarding potential neurotoxicity andhepatotoxicity. ${ }^{18}$

No hematological toxic effects were reported in phase 1 trials for sutezolid $600 \mathrm{mg}$ twice a day for 28 days, which was thought to reduce the inhibition of mitochondrial protein synthesis. Sutezolid dose of 600 mg twice a day and 1,200 mg once a day were well tolerated and showed sputum EBA in patients with TB. ${ }^{7}$

\section{Repurposed Drugs}

The repurposed drugs have been used for MDRTB and XDR-TB treatment while being evaluated ofnew DR-TB drugs and regimens. Fluoroquinolones, kanamycin, amikacin, clofazimine, linezolid, carbapenem, and amoxicillin/clavulanic acid are repurposed drugs. The $3^{\text {rd }}$ and $4^{\text {th }}$ generation of fluoroquinolones (levofloxacin, moxifloxacin, and gatifloxacin) are often used for the treatment of $\mathrm{H}$ monoresistant $\mathrm{TB}$ and MDR-TB, which are the most important components in second-line drugs. ${ }^{19,20}$ As fluoroquinolone is widely available and is used for treating several infectious diseases, it is important to consider the potential for resistance in patients who are not diagnosed with TB and treated with fluoroquinolone. ${ }^{21}$ The antileprosy drug, clofazimine, has shown sterilising activity and treatment-shortening potential. A new rimino- phenazine, TBI-166, has entered phase 1 trials and will hopefully not produce skin discolouration, a common adverse effect of clofazimine. ${ }^{3}$

Linezolid has been reported as a failing regimen on 39 XDR-TB patients with sputum culture conversion on solid media was $35 \%$ after 2 months and $87 \%$ after 6 months. $82 \%$ patients experienced linezolid toxicities, resulting in 3 patients permanently discontinued from linezolid. Based on these results, research on linezolid was conducted to identify the optimal dose to minimize toxicity without reducing their efficacy. ${ }^{22}$ Linezolid was effective in achieving culture conversion, but $82 \%$ of patients experienced adverse effects such as myelosuppression, peripheral neuropathy, and optic neuropathy. Patients who received $300 \mathrm{mg}$ per day experienced fewer adverse effects than $600 \mathrm{mg}$ per day, but it can cause resistance. ${ }^{3}$

Carbapenem may play a role in MDR-TB regimen based on in vitro activity and case reports. Initial trials of faropenem and meropenem are ongoing. Sulfonamides have also been proposed as anti-TB drugs based on the sensitivity in vitro, but no prospective trialshave been conducted. Several prophylactic cotrimoxazole studies in HIV patients in Africa have reported no effect on TB. ${ }^{6}$ Meta-analyzes and systematicreviews of carbapenem use (ertapenem, imipenem, meropenem) for MDR-TB and XDR-TB treatment showed good tolerance and safety records, but the absence of active oral formulations and the need forcombination of amoxicillin and clavulanic acid (which keeps meropenem and carbapenems from $\beta$ lactamases) reduced the activity of carbapenems. ${ }^{3}$ Recent reviews mentioned 6 drugs with antimicrobial activity against Mycobacterium tuberculosis (phenothiazine, metronidazole, doxyxycline, disulfiram, tigecycline, and co-trimoxazole) which appeared to be promising and areproposed to be anti-TB drugs based on in vitrosensitivity tests, but there are no prospective trials performed. ${ }^{21}$

\section{Latent Tuberculosis Treatment}

Latent tuberculosis infection (LTBI) is apersistent immune response to the stimulation of Mycobacterium tuberculosis antigen without clinically manifested symptoms of active TB disease. ${ }^{21}$ A person with LTBI does not have any symptoms and does not transmit TB, but if Mycobacterium tuberculosis in LTBI person becomes active, it will become TB disease. Prevention of active TB disease with LTBI treatment is also an important component in the end of TB strategyby 2035.

WHO recommended LTBI treatment including a weekly dose of rifapentine and isoniazid for 3 months (3HP), a daily dose of rifampicin plus isoniazid for 3 months (3RH), a daily dose of rifampicin for 4 months 
(4R), and a daily dose of isoniazid for 6 months $(6 \mathrm{H})$ or longer. In July 2019, WHO updated the 2018 guidelines based on the new evidence of the use of 2 other TB preventive treatment regimens: $4 \mathrm{R}$ in high $\mathrm{TB}$ burden settings and 1 month of daily isoniazid and rifapentine (1HP). Updated recommendations will be published in the first quarter of $2020 .{ }^{21}$ Rifapentine is given once in a week with combination of isoniazid for LTBI. ${ }^{12}$ ATS recommends LTBI treatment for people in contacts with patients with MDR-TB using a later generation of fluoroquinolone or single therapy using $2^{\text {nd }}$ line drug for 6 to 12 months of treatment, based on the drug susceptibility of the source-case Mycobacterium tuberculosis isolate, followed with observation alone (conditional recommendation, very low certainty in the evidence). If there are evidence of increased toxicity, adverse events, and discontinuations, pyrazinamide should not be routinely used as the second drug. ${ }^{17}$

Clinicians and patients have long desired shorter, more tolerable, and safer alternatives for treatment of
LTBI rather than standardized daily isoniazid for 9 months or more. In 2011, the phase 3 TB TC Study 26 (NCT00164450), undertaken in 7,731 participants, showed non-inferiority of weekly rifapentine and isoniazid (given for 3 months), when compared with 9 months of daily isoniazid. Rifapentine is still unavailable in most countries worldwide. So far, no data are available from phase 3 trials to eradicate latent infection due to drug-resistant Mycobacterium tuberculosis, though two trials are underway assessing 6 months of daily levofloxacin versus placebo, and a large trial will soon begin assessing 6 months of daily delamanid versus 9 months of daily isoniazid, in adults and children. Drugresistant LTBI is a high priority for the control of the growing DR-TB threat. Table 4 below summarized the trials that are being and will be conducted to examine chemoprophylaxis for individuals exposed to TB and DR$\mathrm{TB}$, which are being prepared or will be performed as soon as possible. ${ }^{3}$

Table 4. Ongoing and planned trials for the treatment of latent tuberculosis infection ${ }^{3}$

\begin{tabular}{|c|c|c|c|c|}
\hline 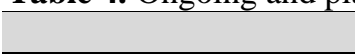 & Phase & Study population & Study groups & Notes \\
\hline \multicolumn{5}{|l|}{$\begin{array}{l}\text { Drug-susceptible } \\
\text { infection }\end{array}$} \\
\hline A5279 (NCT01404312) & 3 & $\begin{array}{l}3,000, \text { HIV }+ \text { adults }(\text { aged } \\
\geq 18 \text { years) }\end{array}$ & $\begin{array}{l}1 \text { month isoniazid }(300 \mathrm{mg}) \text { and } \\
\text { rifapentine }(600 \mathrm{mg}) \text { daily vs } 9 \\
\text { months isoniazid }(300 \mathrm{mg}) \text { daily }\end{array}$ & $\begin{array}{l}\text { Opened May, 2012, } \\
\text { results March, 2018; } \\
\text { pharmacokinetic } \\
\text { substudy of } \\
\text { rifapentine and } \\
\text { efavirenz completed; } \\
\text { ACTG }\end{array}$ \\
\hline $\begin{array}{l}\text { CORTIS, CORTIS-HR } \\
(\text { NCT02735590) }\end{array}$ & 3 & $\begin{array}{l}3,200, \text { HIV- adults (aged } \\
\geq 18 \text { years) and } 860 \text { HIV+ } \\
\text { adults (aged } \geq 18 \text { years), } \\
\text { stratified by risk of active } \\
\text { TB is bytranscriptomics }\end{array}$ & $\begin{array}{l}12 \text { doses isoniazid (maximum } \\
900 \mathrm{mg} \text { ) and rifapentine ( } 900 \\
\mathrm{mg} \text { ) weekly } v \text { so intervention }\end{array}$ & $\begin{array}{l}\text { Opened July, 2016, } \\
\text { results September, } \\
\text { 2018; University of } \\
\text { Cape Town Lung } \\
\text { Institute }\end{array}$ \\
\hline $\begin{array}{l}\text { WHIP3TB } \\
\text { (NCT02980016) }\end{array}$ & 3 & $\begin{array}{l}4,000, \mathrm{HIV}-\text { and } \mathrm{HIV}+ \\
\text { adults (aged } \geq 18 \text { years) }\end{array}$ & $\begin{array}{l}12 \text { doses isoniazid (maximum } \\
900 \mathrm{mg} \text { ) and rifapentine (900 } \\
\mathrm{mg}) \text { weekly in year } 1 \text {, or } 12 \\
\text { doses isoniazid }(900 \mathrm{mg}) \text { and } \\
\text { rifapentine }(900 \mathrm{mg}) \text { weekly in } \\
\text { years } 1 \text { and } 2 \mathrm{vs} 6 \text { months } \\
\text { isoniazid ( } 300 \mathrm{mg} \text { ) daily in year } \\
1\end{array}$ & $\begin{array}{l}\text { Opened November, } \\
\text { 2016, results } \\
\text { September, 2019; } \\
\text { South Africa; Aurum } \\
\text { Institute }\end{array}$ \\
\hline $\begin{array}{l}\text { IMPAACT 2001 } \\
(\text { NCT02651259) }\end{array}$ & $1 / 2$ & $\begin{array}{l}82, \mathrm{HIV}-\text { and } \mathrm{HIV}+ \\
\text { pregnant or lactating women } \\
\text { (aged } \geq 18 \text { years) }\end{array}$ & $\begin{array}{l}\text { Pharmacokinetics, safety: } 12 \\
\text { doses isoniazid (maximum } 900 \\
\mathrm{mg} \text { ) and rifapentine (900 mg) } \\
\text { weekly }\end{array}$ & $\begin{array}{l}\text { Opened February, } \\
\text { 2017; results } \\
\text { December, 2018; } \\
\text { IMPAACT }\end{array}$ \\
\hline TBTC Study 35 & 2 & $\begin{array}{l}\text { 80, } \mathrm{HIV}-\text { and } \mathrm{HIV}+\text { childrer } \\
\text { (aged }<12 \text { years) }\end{array}$ & $\begin{array}{l}\text { Pharmacokinetics, safety: } 12 \\
\text { doses weekly rifapentine }(2535 \\
\mathrm{mg} / \mathrm{kg}) \text { plus isoniazid }(1015 \\
\mathrm{mg} / \mathrm{kg}) \text { in children aged }<2,2-5 \text {, } \\
\text { and } 6-12 \text { years }\end{array}$ & $\begin{array}{l}\text { Opens March, 2018, } \\
\text { results 2021; South } \\
\text { Africa; CDC TBTC, } \\
\text { Sanofi }\end{array}$ \\
\hline
\end{tabular}




\begin{tabular}{|c|c|c|c|c|}
\hline fection & & & & \\
\hline $\begin{array}{l}\text { V-QUIN MDR } \\
\text { (ACTRN1261600021542 } \\
6 \text { ) }\end{array}$ & 3 & $\begin{array}{l}2,006, \mathrm{HIV}-\text { and } \mathrm{HIV+} \\
\text { adults and children (aged } \\
\geq 15 \text { years) }\end{array}$ & $\begin{array}{l}6 \text { months levofloxacin }(250, \\
500, \text { or } 750 \mathrm{mg}) v s \text { placebo } \\
\text { (blinded, cluster randomized) }\end{array}$ & $\begin{array}{l}\text { Opened, 2016, } \\
\text { results, 2019; } \\
\text { Vietnam, Australia; } \\
\text { NHMRC }\end{array}$ \\
\hline $\begin{array}{l}\text { AP } \\
\text { 2634082) }\end{array}$ & 5 & $\begin{array}{l}\text { HIV+ } \\
\text { years) }\end{array}$ & $\begin{array}{l}6 \text { months levofloxacin (15-20 } \\
\text { mg/kg daily) vs placebo } \\
\text { (blinded, cluster randomized) }\end{array}$ & $\begin{array}{l}\text { Opened late } 2017, \\
\text { results, 2021; South } \\
\text { Africa; BMRC }\end{array}$ \\
\hline $\begin{array}{l}\text { ACTG } \\
\text { A5300B/IMPAACT } \\
\text { I2003B PHOENIx }\end{array}$ & 3 & $\begin{array}{l}3,452, \mathrm{HIV}-\text { and } \mathrm{HIV}+ \\
\text { adults and children (aged } \geq 6 \\
\text { years) }\end{array}$ & $\begin{array}{l}6 \text { months delamanid (maximum } \\
200 \mathrm{mg} \text { once daily) vs } 9 \text { months } \\
\text { isoniazid ( } 300 \mathrm{mg} \text { daily) }\end{array}$ & $\begin{array}{l}\text { mid-2018; } \\
\text { IMPAACT }\end{array}$ \\
\hline \multicolumn{5}{|c|}{$\begin{array}{l}\text { CDCTBTC = Centers for Disease and Prevention Tuberculosis Trials Consortium. IMPAACT = International Materna } \\
\text { Pediatric Adolescent AIDS Clinical Trials Network. NHMRC = Australia National Health and Medical Research } \\
\text { Council. BMRC = British Medical Research Council. ACTG = AIDS Clinical Trials Group. }\end{array}$} \\
\hline
\end{tabular}

\section{CONCLUSION}

The treatment of DR TB has grown fast over the past few years. A new, shorter MDR-TB regimens and an increase in the availability of new or repurposed drugs is needed. Management of TB and DR-TB will be updated any time according to the latest findings to evaluate and improve the effectiveness of current treatments. The treatment of latent TB is one of theefforts to control TB to reach the end of TB 2035. Therefore, the development of new drugs for the treatment of LTBI is also very important.

\section{REFERENCES}

1. Organization WH. Global Tuberculosis Report 2020. Geneva, https://www.who.int/publications/i/item/97892400 13131 (2020).

2. Organization WH. Multidrug and Extensively DrugResistant TB (M/XDR-TB): 2010 GlobalReport on Surveillance and Response. Geneva, https://www.who.int/tb/features_archive/m_xdrtb_f acts/en/ (2010).

3. Tiberi S, du Plessis N, Walzl G, et al. Tuberculosis: Progress and Advances in Development of New Drugs, Treatment Regimens, and Host-Directed Therapies. Lancet Infect Dis 2018; 18: e183-e198.

4. Ahmad Khan F, Salim MAH, du Cros P, et al. Effectiveness and Safety of Standardised Shorter Regimens for Multidrug-Resistant Tuberculosis: Individual Patient Data and Aggregate Data MetaAnalyses. Eur Respir J; 50. Epub ahead of print July 2017. DOI: 10.1183/13993003.00061-2017.

5. Hughes J, Isaakidis $P$, Andries A, et al. Linezolid in Drug-Resistant Tuberculosis: Haste Makes Waste. Eur Respir J 2015; 46: 1844 LP - 1846.

6. Wallis RS, Maeurer M, Mwaba $\mathrm{P}$, et al. Tuberculosis--Advances in Development of New Drugs, Treatment Regimens, Host-Directed Therapies, and Biomarkers. Lancet Infect Dis2016; 16: e34-46.

7. Tiberi S, Muñoz-Torrico M, Duarte R, et al. New Drugs and Perspectives for New Anti-Tuberculosis Regimens. Pulmonology 2018; 24: 86-98.
8. Falzon D, Schünemann HJ, Harausz E, et al. World Health Organization Treatment Guidelines forDrugResistant Tuberculosis, 2016 Update. Eur Respir J; 49. Epub ahead of print March 2017. DOI: 10.1183/13993003.02308-2016.

9. Organization WH. WHO Consolidated Guidelines on Tuberculosis, Module 4: Treatment - Drug-

Resistant Tuberculosis Treatment. Geneva, https://www.who.int/publications/i/item/97892400 07048 (2020).

10. Ahmad N, Ahuja SD, Akkerman OW, et al. Treatment Correlates of Successful Outcomes in Pulmonary Multidrug-Resistant Tuberculosis: An Individual Patient Data Meta-Analysis. Lancet2018; 392: 821-834.

11. Organization WH. Guidelines for Treatment of Drug-Susceptible Tuberculosis and Patient Care (2017 Update). Geneva, https://www.who.int/tb/publications/2017/dstb_gui dance_2017/en/ (2017).

12. Nahid P, Dorman SE, Alipanah N, et al. Official American Thoracic Society/Centers for Disease Control and Prevention/Infectious DiseasesSociety of America Clinical Practice Guidelines: Treatment of Drug-Susceptible Tuberculosis. Clin Infect Dis an Off Publ Infect Dis Soc Am 2016; 63: e147e195.

13. Indonesia KKR. Panduan Pelayanan Tuberkulosis Resistan Obat untuk Fasilitas Pelayanan Kesehatan. Jakarta, 2019.

14. Kuaban C, Noeske J, Rieder HL, et al. High Effectiveness of a 12-Month Regimen for MDR-TB Patients in Cameroon. Int J Tuberc Lung Dis Off $J$ Int Union against Tuberc Lung Dis 2015; 19: 517524.

15. Piubello A, Harouna SH, Souleymane MB, et al. High Cure Rate with Standardised Short-Course Multidrug-Resistant Tuberculosis Treatment in Niger: No Relapses. Int J Tuberc lung Dis Off J Int Union against Tuberc Lung Dis 2014; 18: 11881194.

16. Harausz E, Cox H, Rich M, et al. QTc Prolongation and Treatment of Multidrug-Resistant Tuberculosis. Int J Tuberc lung Dis Off J Int Union against Tuberc Lung Dis 2015; 19: 385-391.

17. Nahid P, Mase SR, Migliori GB, et al. Treatment 
of Drug-Resistant Tuberculosis. An Official ATS/CDC/ERS/IDSA Clinical Practice Guideline. Am J Respir Crit Care Med 2019; 200: e93-e142.

18. Olaru ID, von Groote-Bidlingmaier F, Heyckendorf J, et al. Novel Drugs against Tuberculosis: A Clinician's Perspective. Eur Respir J 2015; 45: 1119-1131.

19. Guglielmetti L, Le Dû D, Veziris N, et al. Is Bedaquiline as Effective as Fluoroquinolones inthe Treatment of Multidrug-Resistant Tuberculosis? Eur Respir J 2016; 48: 582 LP - 585.
20. Falzon D, Gandhi N, Migliori GB, et al. Resistance to Fluoroquinolones and Second-Line Injectable Drugs: Impact on Multidrug-Resistant TB Outcomes. Eur Respir J 2013; 42: 156-168.

21. Tiberi S, Buchanan R, Caminero JA, et al. The Challenge of the New Tuberculosis Drugs. Presse Med 2017; 46: e41-e51.

22. Lee M, Lee J, Carroll MW, et al. Linezolid for Treatment of Chronic Extensively Drug-Resistant Tuberculosis. N Engl J Med 2012; 367: 1508- 1518. 